\title{
Commentary: Is there strength in frailty testing?
}

\author{
Thomas E. MacGillivray, MD, and \\ Michael J. Reardon, MD \\ "Not everything that can be counted counts, and not \\ everything that counts can be counted."
}

-William Bruce Cameron

The risks a patient assumes when undergoing a surgical procedure is of great concern to both the patient and his or her treating physician(s). Multiple risk scores have been developed, the most common in North America being the Society of Thoracic Surgeons short-term risk calculator, which was last updated during November 2018. Cardiac surgeons have used this risk calculator in conjunction with an estimate based on their prior experience and how the patient appears to them; that is, the eyeball test. Symptomatic severe aortic stenosis carries a high mortality when left untreated, and aortic valve replacement is the only treatment ever shown to improve survival. Until recently, surgical aortic valve replacement (SAVR) was the only option. Since the first successful transcatheter aortic valve implantation (TAVI) in 2002, ${ }^{1}$ we have seen a series of randomized trials studying extreme, high, intermediate, and finally lowsurgical-risk patients. ${ }^{2-7}$ These trials all supported the use of TAVI in the populations tested. The result of this data deluge is the current 2020 American College of Cardiology/American Heart Association valve guidelines recommendation for SAVR versus TAVI. ${ }^{8}$ Risk is no longer a stand-alone factor in this decision. The guidelines have divided patients into 3 broad categories for patients with symptomatic severe aortic stenosis who are candidates for a bioprosthetic valve. For patients younger than age 65 years and likely to have a 20 -year life expectancy, SAVR is

From the Department of Cardiovascular Surgery, Houston Methodist Hospital, Houston, Tex.

Disclosures: The authors reported no conflicts of interest.

The Journal policy requires editors and reviewers to disclose conflicts of interest and to decline handling or reviewing manuscripts for which they may have a conflict of interest. The editors and reviewers of this article have no conflicts of interest

Received for publication March 4, 2021; revisions received March 4, 2021; accepted for publication March 5, 2021; available ahead of print March 10, 2021.

Address for reprints: Michael J. Reardon, MD, Department of Cardiovascular Surgery, Houston Methodist Hospital, 6550 Fannin St, Suite 1401, Houston, TX 77030 (E-mail: mreardon@houstonmethodist.org).

J Thorac Cardiovasc Surg 2023;165:1484-5

$0022-5223 / \$ 36.00$

Copyright (c) 2021 by The American Association for Thoracic Surgery

https://doi.org/10.1016/j.jtcvs.2021.03.020

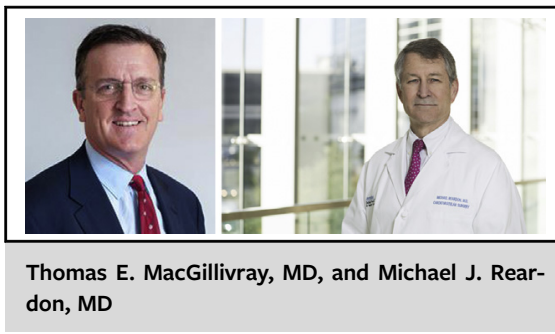

CENTRAL MESSAGE

Understanding the risks of cardiac surgery in elderly patients is extremely important. Identifying the risk factors that truly count and influence outcomes is

crucial.

recommended. At the other end of the age spectrum-patients aged 80 years or older with a life expectancy $<10$ years who are anatomically appropriate for a transfemoral TAVI-TAVI is preferred. In the 65 to 80 years age range, the middle range appropriate for a transfemoral TAVI, shared decision making that balances patientexpected longevity, potential valve durability, and the perceived risks of SAVR and TAVI is recommended. With a guideline recommendation for TAVI over SAVR in patients older than age 80 years, it is important to understand that this will not apply to all patients in this age group. Understanding the outcomes and how best to predict them in making this decision for those who might not be optimal candidates for TAVI has gained great importance.

Lim and colleagues ${ }^{9}$ explore surgical risk in selected patients aged $\geq 80$ years having cardiac surgery requiring sternotomy and cardiopulmonary bypass in their institution and the influence of frailty on the short- and midterm outcomes. They looked at 200 patients (from 366, the majority not enrolled due to time constraints) between 2016 and 2019. The mean age was 82.8 years. Four frailty tests were applied to each patient. The 5-minute walk test (5MWT), the timed up and go test, the 5 time stand and sit test, and the handgrip strength test. All the frailty tests were performed by a single physical therapist. The cutoff for positive frailty was 5MWT ( $>6.4$ seconds), timed up and go test ( $>18.4$ seconds), 5 time stand and sit test ( $>13.6$ seconds) and handgrip strength test $(<21.33 \mathrm{~kg}$.) The purpose of the study was to define the effect these frailty measures had in predicting mortality, morbidity, and functional outcomes. There were 3 in-hospital deaths $(1.5 \%)$, all in the 
slow 5MWT group and 1-year survival was $98.7 \%$ versus $91.5 \%$ for the normal versus the slow 5MWT groups. Of the frailty tests, only the 5MWT was an independent predictor of adverse clinical outcome and was associated with significantly diminished 1-year survival. Additionally, more than half of those with a slow walk time required discharge to a longer-term health facility. Quality of life as measured by the Short Form Survey 12 was appropriate for age in the normal Canadian population in all groups, although only $99(51.6 \%)$ of patients completed this form.

Lim and colleagues ${ }^{9}$ have added to our decision-making tools through their research efforts. The 5MWT is simple to execute and we have added this to the evaluation of all cardiac surgery patients at all ages. We also want to commend them on their truly outstanding survival data. A $1.3 \%$ mortality for octogenarians is outstanding. Even more impressive is the 1-year survival of $98.7 \%$ in those without a slow 5MWT. Based on US life table analysis, the probability of an American man aged 82 years dying during the next year is $7.07 \%$ (for women it is $5.32 \%) .{ }^{10}$ Lim and colleagues, ${ }^{9}$ Canadian normal-walkspeed group is living longer than the normal US population. Maybe Canadians just live longer? That brings us back to a more focused interest of ours, the treatment of symptomatic severe aortic stenosis. I agree with the guidelines that most patients older than age 80 years and anatomically appropriate for transfemoral TAVI should be treated with TAVI if the patient wishes. Lim and colleagues" ${ }^{9}$ Table E5 shows that perioperative outcomes included acute renal failure in $21.5 \%$, deep sternal wound infection in $0.5 \%$, delirium in $25 \%$, prolonged ventilation in $3.5 \%$, new atrial fibrillation in $36 \%$, transfusion in $72 \%$, an intensive care unit length of stay of 1.2 days, and hospital length of stay of 8 days. Current outcomes would be better with TAVI compared with SAVR based on metrics seen in the randomized trials. When assessing a patient older than age 80 years in need of cardiac surgery, Lim and colleagues ${ }^{9}$ have shown us that expert surgeons, in an expert center, can appropriately select patients and achieve excellent outcomes. In areas such as aortic stenosis, where a nonsurgical approach can be available, most patients older than age 80 years may do better with TAVI. We should remember that surgery can still be a reasonable choice in appropriately selected patients. They should not be considered categorically as nonsurgical candidates and choosing the appropriate patient when SAVR appears more desirable is important. This article furthers our understanding of how best to predict risk and select the appropriate older patients for cardiac surgery by counting the things that count.

\section{References}

1. Cribier A, Eltchaninoff H, Bash A, Borenstein N, Tron C, Bauer F, et al. Percutaneous transcatheter implantation of an aortic valve prosthesis for calcific aortic stenosis: first human case description. Circulation. 2002;106:3006-8.

2. Smith CR, Leon MB, Mack MJ, Miller DC, Moses JW, Svensson LG, et al. Transcatheter versus surgical aortic-valve replacement in high-risk patients. $N$ Engl J Med. 2011;364:2187-98.

3. Adams DH, Popma JJ, Reardon MJ, Yakubov SJ, Coselli JS, Deeb GM, et al. Transcatheter aortic-valve replacement with a self-expanding prosthesis. $N$ Engl J Med. 2014;370:1790-8.

4. Leon MB, Smith CR, Mack MJ, Makkar RR, Svensson LG, Kodali SK, et al. Transcatheter or surgical aortic-valve replacement in intermediate-risk patients. N Engl J Med. 2016;374:1609-20.

5. Reardon MJ, Van Mieghem NM, Popma JJ, Kleiman NS, Søndergaard L, Mumtaz M, et al. Surgical or transcatheter aortic-valve replacement in intermediate-risk patients. N Engl J Med. 2017;376:1321-31.

6. Mack MJ, Leon MB, Thourani VH, Makkar R, Kodali SK, Russo M, et al. Transcatheter aortic-valve replacement with a balloon-expandable valve in low-risk patients. N Engl J Med. 2019;380:1695-705.

7. Popma JJ, Deeb GM, Yakubov SJ, Mumtaz M, Gada H, O'Hair D, et al. Transcatheter aortic-valve replacement with a self-expanding valve in low-risk patients. N Engl J Med. 2019;380:1706-15.

8. Otto CM, Nishimura RA, Bonow RO, Carabello BA, Erwin JP III, Gentile F, et al. 2020 ACC/AHA guideline for the management of patients with valvular heart disease: a report of the American College of Cardiology/American Heart Association Joint Committee on clinical practice guidelines. Circulation. 2021;143: e72-227.

9. Lim S, Jacques F, Babaki S, Babaki Y, Simard S, Kalavrouziotis D, et al. Preoperative physical frailty assessment among octogenarians undergoing cardiac surgery: upgrading the "eyeball" test. J Thorac Cardiovas Surg. 2023;165:1473-83.e9.

10. US Social Security Administration. 2014 SSA period life table. Available at: https://www.ssa.gov/OACT/HistEst/PerLifeTables/2014/PerLifeTables2014.html. Accessed March 15, 2021. 